Abstracta Iranica Abstracta Iranica

Revue bibliographique pour le domaine irano-aryen

Volume 34-35-36 | 2017

Comptes rendus des publications de 2011-2013

\title{
Pierre Briant. From the Indus to the Mediterranean: The Administrative Organisation and Logistics of the Great Roads of the Achaemenid Empire
}

\section{Rémy Boucharlat}

\section{(2) OpenEdition \\ Journals}

Édition électronique

URL : http://journals.openedition.org/abstractairanica/42140

DOI : 10.4000/abstractairanica.42140

ISSN : 1961-960X

Éditeur :

CNRS (UMR 7528 Mondes iraniens et indiens), Éditions de l'IFRI

Référence électronique

Rémy Boucharlat, «Pierre Briant. From the Indus to the Mediterranean: The Administrative Organisation and Logistics of the Great Roads of the Achaemenid Empire », Abstracta Iranica [En ligne], Volume 34-35-36 | 2017, document 121, mis en ligne le 30 juillet 2017, consulté le 02 octobre 2020. URL http://journals.openedition.org/abstractairanica/42140; DOI : https://doi.org/10.4000/

abstractairanica. 42140

Ce document a été généré automatiquement le 2 octobre 2020.

Tous droits réservés 


\title{
Pierre Briant. From the Indus to the Mediterranean: The Administrative Organisation and Logistics of the Great Roads of the Achaemenid Empire
}

\author{
Rémy Boucharlat
}

\section{RÉFÉRENCE}

Pierre Briant. « From the Indus to the Mediterranean: The Administrative Organisation and Logistics of the Great Roads of the Achaemenid Empire », in: S.E. Alcock, J. Bodel and J.A. Talbert, eds., Highways, Byways and Road Systems in the Pre-Modern World. New York, Wiley, 2012, p. 185-201.

1 La description par Hérodote de la route royale de Sardes à Suse, qui est en fait liée au voyage particulier d'un Spartiate en Orient, est " l'arbre qui cache la forêt » sur la réalité du réseau viaire de l'empire achéménide. Cette route n'est qu'un segment parmi d'autres, important puisqu'il mène à une résidence royale. Les témoignages chez les auteurs grecs sont rares; toutefois Ctésias mentionne la route d'Ephèse à la Bactriane et à l'Inde, Xénophon décrit l'itinéraire des Dix-Mille, les historiens d'Alexandre montrent que celui-ci connaissait les routes de l'empire, quitte à les éviter parfois par tactique. Mais les sources les plus importantes sont les tablettes de Persépolis, témoignages limités dans le temps (509-494 av. n. è.) mais très éclairants, car « vus depuis le Centre ». La série $Q$ de ces tablettes, des documents sur les « rations de voyage " montrent toute la précision de l'organisation des voyages pour lesquels les stations ou relais recevaient à l'avance des stocks qui permettaient aux voyageurs de trouver à l'étape la nourriture nécessaire pour eux et les animaux. Il s'agit de déplacements de quelques personnes ou bien de plusieurs centaines, non pas tant des troupes que des nobles et leur suite, et très souvent des artisans et ouvriers envoyés d'une ville ou résidence à une autre. Les déplacements de Persépolis à Suse sont bien documentés, 
mais aussi ceux vers d'autres régions à l'ouest, Médie, et bien au-delà, et Egypte, ou à l'est Drangiane, Arachosie, Arie, Hindoush. Le système administratif visait à l'efficacité économique certainement, mais aussi probablement au contrôle par le pouvoir central relayé dans les provinces par les satrapes qui rendaient des comptes.

\section{AUTEURS}

\section{RÉMY BOUCHARLAT}

UMR 5133 CNRS-Université de Lyon 